\title{
Analysis of Structural, Optical, and Aquaphobic Properties of Zirconium Oxide Nanofilms by Varying Sputtering Gas
}

\author{
Kumar Sujit $\mathbb{D}^{1},{ }^{1}$ Dave Vikramaditya, ${ }^{2}$ K. Vetri Velmurugan, ${ }^{3}$ Yakkala Bhaskarrao, ${ }^{4}$ \\ Rupali Singh, ${ }^{5}$ Bhasker Pant, ${ }^{6}$ Amit Kumar Sharma $\mathbb{D D}^{7}{ }^{7}$ Hari Kumar Singh, \\ and Lijalem Mulugeta $\mathbb{D}^{9}$ \\ ${ }^{1}$ Department of Electrical and Electronics Engineering, Jain (Deemed-to-be University), Bengaluru 562112, Karnataka, India \\ ${ }^{2}$ Department of Electrical Engineering, College of Technology and Engineering, Udaipur 313001, Rajasthan, India \\ ${ }^{3}$ Department of Mechanical Engineering, Sri Sai Ram Engineering College, Chennai 600044, Tamil Nadu, India \\ ${ }^{4}$ Department of Electronics and Communication Engineering, Saveetha School of Engineering-SIMATS, Chennai, \\ Tamil Nadu 602105, India \\ ${ }^{5}$ Department of Electronics and Communication Engineering, SRM Institute of Science and Technology, Delhi NCR Campus, \\ Ghaziabad 201204, India \\ ${ }^{6}$ Department of Computer Science \& Engineering, Graphic Era Deemed to be University, Dehradun, Uttarakhand 248002, India \\ ${ }^{7}$ Department of Physics, D.A.V. (PG) College, Dehradun, Uttarakhand 248001, India \\ ${ }^{8}$ Department of Electronics and Communication Engineering, Mahatma Jyotiba Phule Rohilkhand University, Bareilly, \\ Uttar Pradesh 243006, India \\ ${ }^{9}$ Department of Mechanical Engineering, Faculty of Manufacturing Institute of Technology, Hawassa University, Hawassa, \\ Ethiopia
}

Correspondence should be addressed to Lijalem Mulugeta; lijalem@hu.edu.et

Received 23 December 2021; Accepted 9 January 2022; Published 30 January 2022

Academic Editor: A Parthiban

Copyright (C) 2022 Kumar Sujit et al. This is an open access article distributed under the Creative Commons Attribution License, which permits unrestricted use, distribution, and reproduction in any medium, provided the original work is properly cited.

\begin{abstract}
The problem of contamination in ceramic insulators was found to be frequent in power transmission lines and transformers. The key aim was to develop aquaphobic zirconium oxide $\left(\mathrm{ZrO}_{2}\right)$ thin films using DC reactive magnetron sputtering over glass insulators to mitigate contamination problems. This was achieved by introducing $\mathrm{O}_{2}$ and $\mathrm{Ar}$ gas in the sputtering chamber, and three properties, namely, structural, optical, and aquaphobic, were inspected by changing the sputtering gas ratio (oxygen/argon). These properties were chosen based on comparison with the bulk $\mathrm{ZrO}_{2}$. These deposited $\mathrm{ZrO}_{2}$ samples were identified by X-ray diffractometer (XRD), atomic force microscopy (AFM), UV-Vis-NIR spectrophotometer, and contact angle goniometer (CAG). For all the samples, coatings were found to be limpid, clear, and aquaphobic. Coarseness $(62.813 \mathrm{~nm})$ and the contact angle made by water to the surface $\left(107.45^{\circ}\right)$ were found utmost as deposited at 0.25 oxygen/argon gas ratios. The transmittance and band gap were also found to be $90 \%$ and $5.33 \mathrm{eV}$, respectively, at this particular ratio.
\end{abstract}

\section{Introduction}

Nearly all transmission line insulators are made with porcelain and toughened glass due to their confirmed record of high trustworthiness of system voltages. Being available in the outside condition, insulator flashover has been an immediate danger to power systems. Under the working voltage, contaminants in blend with dampness bring about a decline in surface protection quality and accordingly initiate the progression of leakage currents. Due to the flow of leakage current, dry bands appear which produce electrical discharges and sparks. At elevated dampness, such sparks may lengthen and produce flashover. As ceramics being high surface vitality materials, water will effectively spread on them, hence diminishing the opposition under clammy and sullied conditions which prompts flashover [1]. A variety of methods are applied to avert contamination discharge. 
This comprises of cleansing, hot bathe or hand sweeping, and lubricant [2]. These methods are labor extensive and are associated with other drawbacks such as extravagant, expensive, and perilous. Aquaphobic coating on the surface of the insulator is found to be another technique to prevent the insulator from flashover [3]. For the last 30 years, room temperature vulcanized (RTV) coating has been used as aquaphobic coating on the surface of the insulator [4]. Since the material is in polymer form, it is characterised with low mechanical potency and as a result of which the material debases very quickly $[5,6]$. Consequently, interest was raised in focusing on the material having high-quality dielectric and mechanical properties in addition to aquaphobicity. Inorganic oxides such as zirconium and titanium are able to be a probable candidate to counter the above problem.

Porcelain and toughened glass made by inorganic materials have high thermal strength [7] and are delicate. Taking into account the inorganic oxides, zirconium dioxide $\left(\mathrm{ZrO}_{2}\right)$ predominantly showed signs of striking features of the high dielectric constant, wide band gap, high melting point, and thermodynamically stable [8-10]. Discussing thin films, these are eminent for their optical and electrical applications. A blend of the high refractive index and low ingestion in the expansive locale of close UV to the mid-IR makes dielectric materials appropriate for applications in defensive mirrors, optical channels, high-reflectivity mirrors, high-power lasers, and other electro-optic gadgets [8,11-19].

$\mathrm{ZrO}_{2}$ has not been counted yet in the text of countering the flashover problem and has not been explored in the aquaphobic property of $\mathrm{ZrO}_{2}$ films. Patel et al. [20] reported the contact angle of $101^{\circ}$ for $\mathrm{ZrO}_{2}$ deposition. Although, very few research studies have been focused on aquaphobic properties. The goal of this is to look at a few significant properties, which support in countering the flashover problem methodically, and the film which was deposited over the glass substrate possesses various properties.

Although there were many methods available [21-26] to deposit $\mathrm{ZrO}_{2}$ films, the same deposition was carried out using DC reactive magnetron sputtering methodology.

\section{Material Synthesis}

Nanostructured $\mathrm{ZrO}_{2}$ film was developed on substrate (glass) using the DC magnetron methodology (Excel Instruments, India). Figure 1 shows the graphical diagram of deposition chamber.

The experiment was started by washing the substrate into supersonic baths of acetone and desiccated for few minutes. Meantime, the chamber was originally emptied by a turbo molecular pump supported by a rotating pump to maintain the pressure of $2 \times 10^{-6}$ Torr. The experiment was setup by the flow rate of pure argon of 40 standard cubic centimeters per minute $(\mathrm{sccm})$ as a constant with the mixture of pure oxygen varied from 10 to $40 \mathrm{sccm}$.

The sputtering was carried out for 90 minutes for all depositions. Table 1 shows the setup environment under the room temperature.

Various properties were examined as follows: the phase identification of zirconium oxide was observed by X-ray

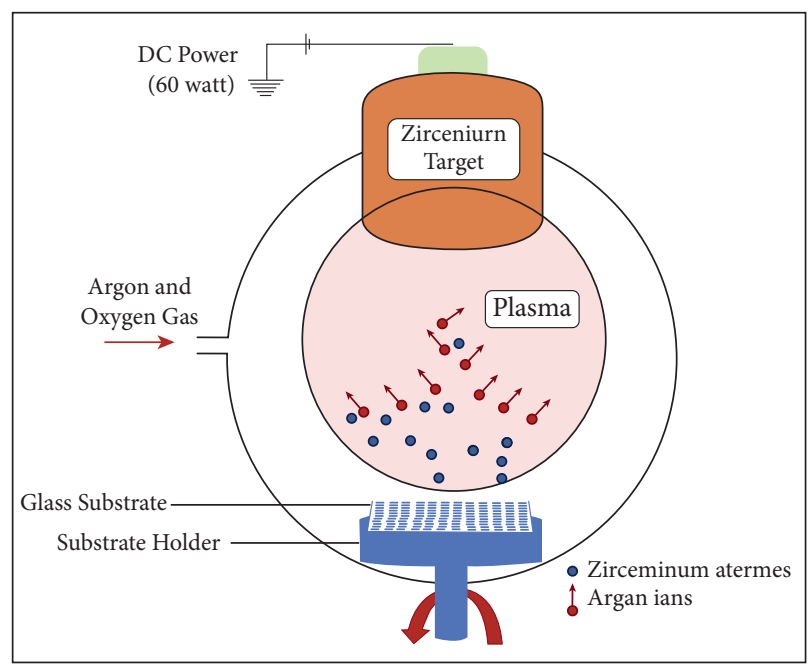

FIGURE 1: Schematic diagram of sputtering chamber.

TABle 1: Environmental parameter for $\mathrm{ZrO}_{2}$ films.

\begin{tabular}{lc}
\hline \multicolumn{2}{c}{ Setup environment under room temperature } \\
\hline Base pressure & $5 \times 10^{-6}$ Torr \\
Working pressure & $15 \mathrm{~m}$ Torr \\
Ar gas flow & $40 \mathrm{sccm}$ \\
$\mathrm{O}_{2} /$ Ar gas ratio range & $0.25-1.25$ \\
Sputtering power & $60 \mathrm{~W}$ \\
\hline
\end{tabular}

power diffraction (XRD), and an atomic force microscopy (AFM) was used to image the topography of materials in their native environments and the microstructure of the films, respectively. An energy dispersive spectroscopy (EDS) attached with a field emission scanning electron microscope (FE-SEM) (FEI, Quanta 200F) was used for carrying out composition investigation of the films. A surface profilometer was opted to calculate the width of the films. Wettability of the film was measured by the contact angle goniometer. The Cary 5000 UV spectrophotometer was used for measuring the ocular diffusion and the inclusion in the range of 200 to $800 \mathrm{~nm}$ wavelength. 4-5 samples were prepared in $\mathrm{O}_{2} / \mathrm{Ar}$ ambiance at different gas ratios, as shown in Table 1.

\section{Results and Discussion}

Zirconium oxide thin film was prepared as deposited by varying oxygen/argon gas ratio from 0.25 to 1.00 . The XRD graph of nanocrystalline $\mathrm{ZrO}_{2}$ in a range of oxygen/argon ratio is shown in Figure 2.

These patterns show two well-defined diffraction peaks corresponding to the planes $(-111)$ at $2 \theta=28.1750$ and (111) at $2 \theta=31.4680$ of the monocrystalline phase (JCPDS 00-0371484). At the gas ratio of 0.25 , the intensity at (-111) is very high. Further increase in the gas ratio from 0.5 to 1.0 decreases (-111) intensity and increases (111) intensity. This behavior is justified as the oxygen concentration increases the kinetic energy of the reactive particles gets reduced in the plasma, which confines the surface dispersion of the 


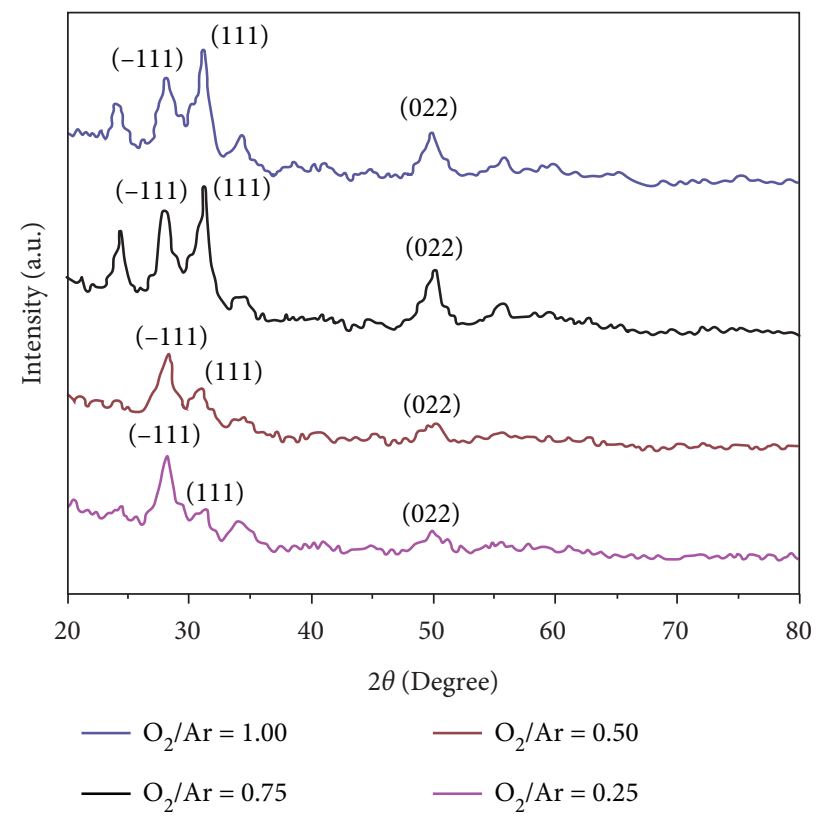

FIgURE 2: XRD outline of prepared $\mathrm{ZrO}_{2}$ at various oxygen/argon gas ratios.

increasing atoms [27]. The highest intensity at 0.25 gas ratio indicates improvement in the crystalline nature when arranged with less oxygen content. An increase in the gas ratio results in decreased film width and as a result debases the film quality. Thus, the increase in oxygen content results in the increased intensity of the (111) plane and a decrease in the intensity of the $(-111)$ direction.

Scherrer's formula tells the grain size which is calculated using equation as follows [28]:

$$
t=0.9 \lambda / \beta \cos \theta \text {. }
$$

Details of the above equation can be found in [28]. Table 2 shows that the grain size decreases significantly with increased oxygen/argon gas ratio. The rate of deposition decreases from $9.05-8.92 \mathrm{~nm} / \mathrm{min}$. This can be explained that decreasing of sticking coefficient results in decreased deposition rate. Through EDS, the composition analysis of zirconium and oxygen is shown in Table 2. The result matching with the hypothetical point $(\mathrm{Zr}=69.88 \%$ and $\mathrm{O}=30.12 \%$ ) was achieved for oxygen/argon at 0.25 ratio.

The 3-D image of the samples in the argon atmosphere is shown in Figure 3.

It evidently replicates that the granule size is bulky for the sample deposited with the low content of oxygen flow (10 $\mathrm{sccm}$ ) that is at 0.25 gas ratio.

Software attached with AFM was used to calculate rms value for surface coarseness. The variation of surface coarseness/roughness with oxygen/argon ratio is shown in Figure 4. It supported the reality that as the grain size decreases, thickness decreases (Table 3) which results in decreased surface coarseness [29]. The maximum coarseness of $62.813 \mathrm{~nm}$ was obtained at a 0.25 oxygen/argon gas ratios. Determining the aquaphobicity of coatings surface coarseness plays a significant role.
The literature review exposed that the surfaces with nanotextures was utilized to shape aquaphobic surfaces [30]. Surface coarseness and the finest contact angle relationship are described in equation as follows [31]:

$$
\cos \theta_{b}=A \cos \theta
$$

Ramana et al. [29] evidently depict that for an aquaphobic case $(\theta b>900)$, as coarseness increases, wettability reduces and contrariwise. Likewise, in an aquaphilic case, coarseness and wettability show a proportional increasing trend. To conclude aquaphobicity, a sessile drop measurement method was used. Difference in water to surface angle with varying gas ratios is shown in Figure 4, which clearly states that water angle and coarseness both decrease as gas ratio increases, and hence, aquaphobicity decreases. The maximum contact angle of $107.45^{\circ}$ was found at 0.25 oxygen/argon gas ratios.

Figure 5 shows spectral transmitivity of the samples prepared under varying oxygen/argon gas ratio. These oscillations, shown in Figure 5, were due to interference effect. Every prepared sample was having the visibility of more than $85 \%$.

Manifacier et al.'s formula [32] shown in equations (3) and (4) was taken into consideration to calculate the index of refraction (refractive index (RI)).

$$
n=\left[N+\left(N^{2}-n_{0}^{2} n_{0}^{1}\right)^{1 / 2}\right]^{1 / 2},
$$

where

$$
N=\left(\frac{n_{0}^{2}+n_{1}^{2}}{2}\right)+2 n_{0} n_{1} \frac{T_{\max }-T_{\min }}{T_{\max } T_{\min }}
$$


TABLE 2: Elemental analysis of $\mathrm{ZrO}_{2}$ in oxygen/argon gas atmosphere.

\begin{tabular}{lcccr}
\hline Oxygen/argon gas ratio & wt $\% \mathrm{Zr}$ & $\mathrm{wt} \% \mathrm{O}$ & Grain size $(\mathrm{nm})$ & Deposition rate $(\mathrm{nm} / \mathrm{min})$ \\
\hline 0.25 & 68.95 & 31.05 & 77.01 & 9.05 \\
0.5 & 68.15 & 31.85 & 65.21 & 9.01 \\
0.75 & 66.82 & 33.18 & 60.13 & 8.98 \\
1.0 & 64.73 & 35.27 & 56.19 & 8.92 \\
1.25 & 64.21 & 35.39 & 54.26 & 8.90 \\
\hline
\end{tabular}
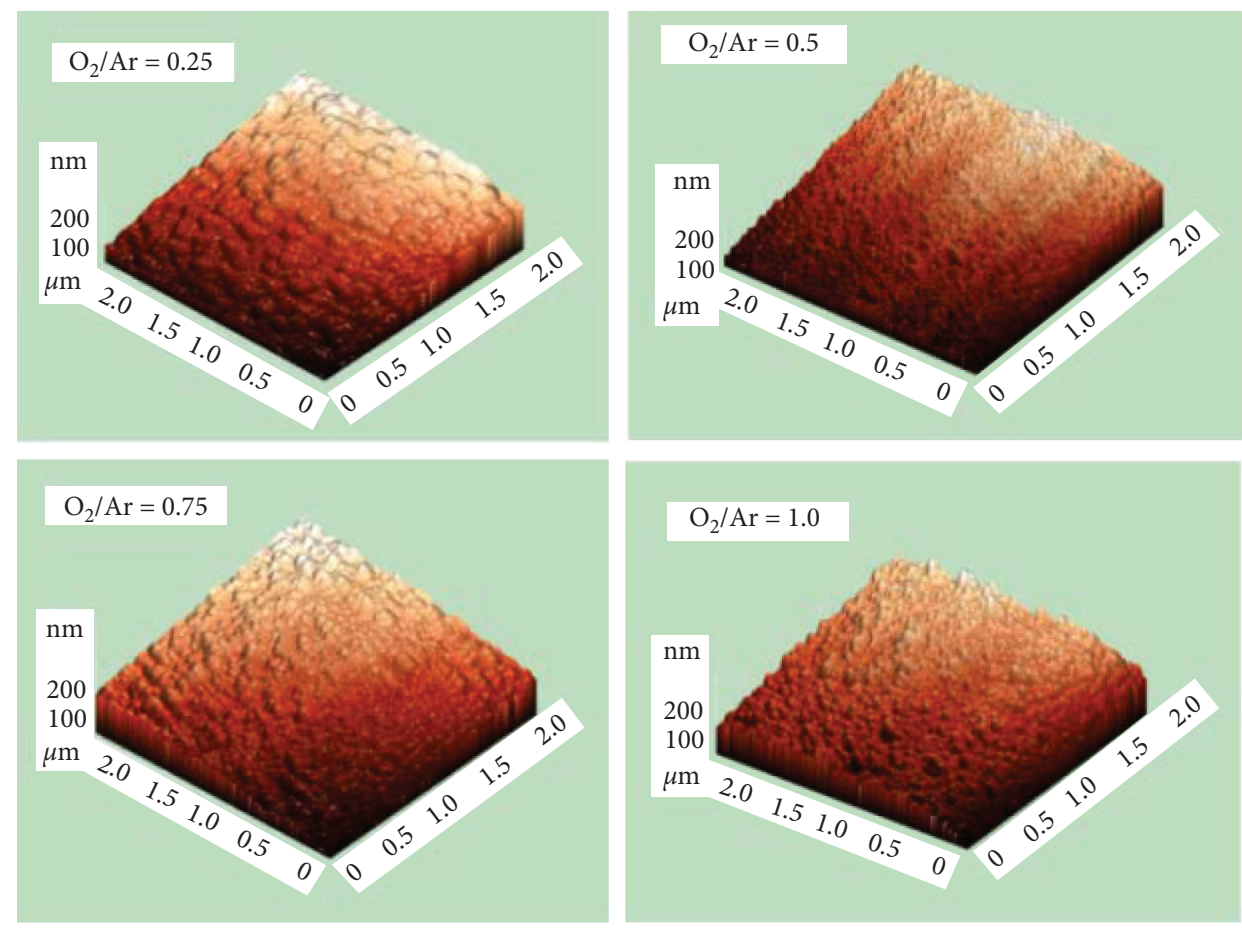

FIGURE 3: Image topology of film prepared at various ratios of oxygen/argon.

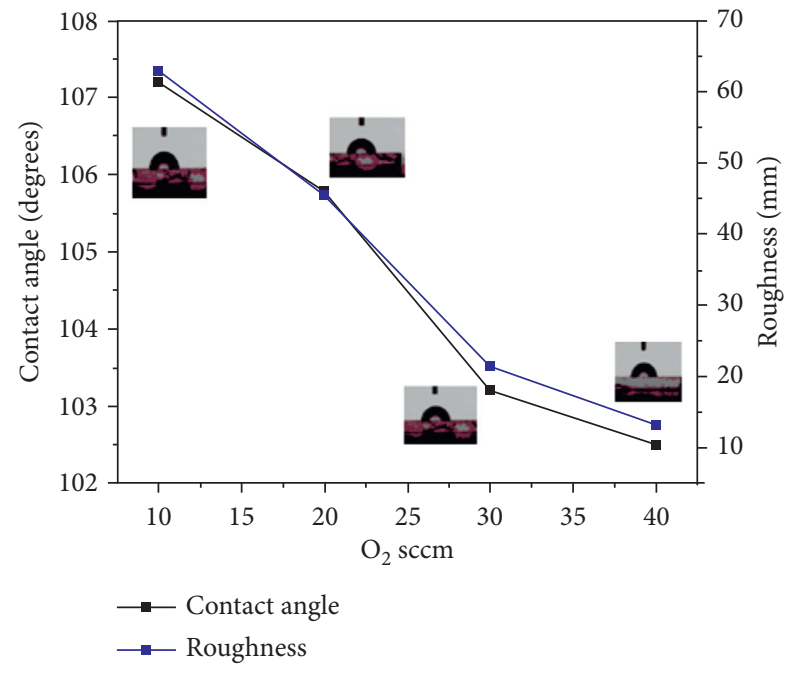

FIgURE 4: Deviation of contact angle and coarseness at various ratios of oxygen/argon.

Table 3 shows RI measured at a wavelength of $550 \mathrm{~nm}$. It is observed that RI decreases with an increased oxygen concentration.
This can be explained that as the $\mathrm{O}_{2}$ concentration increases, the rate of diffusion of $\mathrm{O}_{2}$ into the region of the interfacial layer also increases that results in the arrangement of an unwanted layer among film and substrate. It avoids the increased rate in $\mathrm{ZrO}_{2}$ thin film and thus reduces $\mathrm{RI}$ [33]. The peak RI for the prepared films was found at 0.25. From [34], RI for oxygen/argon gas ratio lies in between 2.07 and 2.15.

From the following relation shown in equations (5) and (6), the coefficients of absorption $(\alpha)$ [35] was measured for $\lambda$ in the range of $200-800 \mathrm{~nm}$.

$$
T \approx\left(1-R_{1}\right)\left(1-R_{2}\right)\left(1-R_{3}\right) \exp (-\alpha d) .
$$

By rearranging, $\alpha$ has been measured using the subsequent estimated formula:

$$
\alpha=\frac{-\ln T /\left(1-R_{1}\right)\left(1-R_{2}\right)\left(1-R_{3}\right)}{d} .
$$

From Tauc's relation, equation (7) [36] band gap (Eg) was determined which helped in obtaining $\alpha$ coefficient:

$$
Z=\alpha h v=k\left(h v-E_{g}\right)^{n}
$$

The value of $n$ was taken as 2 for direct allowed transitions [34] since $\mathrm{ZrO}_{2}$ is considered as a material with direct 
TABLE 3: Parameters found for $\mathrm{ZrO}_{2}$ films at various ratios of oxygen/argon.

\begin{tabular}{lccccc}
\hline Ratio & RI & Band gap & Ocular data & \multicolumn{2}{c}{ Film thickness (nm) measured } \\
& & & 815 & 813 & 809 \\
0.25 & 2.15 & 5.33 & 811 & 808 & 804 \\
0.50 & 2.13 & 5.37 & 809 & 805 & 801 \\
0.75 & 2.10 & 5.42 & 803 & 795 & 789 \\
1.00 & 2.08 & 5.45 & 789 & 780 & 773 \\
1.25 & 2.07 & 5.48 & & & Surface profilometer \\
\hline
\end{tabular}

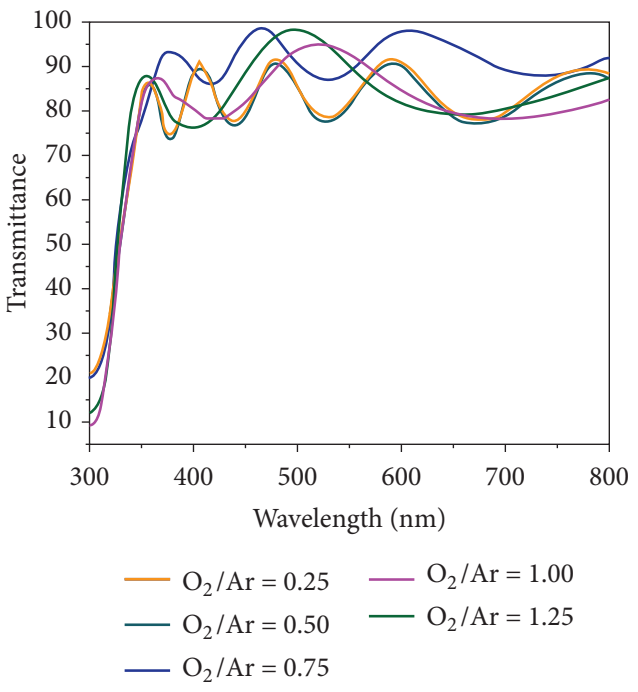

FIGURE 5: Spectral transmitivity of $\mathrm{ZrO}_{2}$ at various ratios of oxygen/ argon.

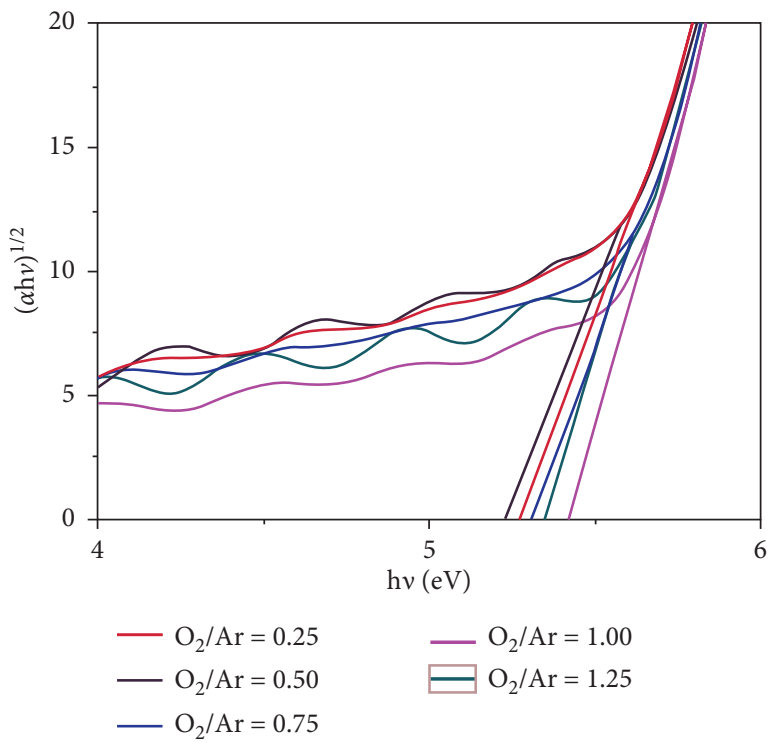

Figure 6: Band gap of $\mathrm{ZrO}_{2}$ at various ratios of oxygen/argon.

band gap energy and 3 for indirect-forbidden transitions. Figure 6 shows the graph between $(\alpha h v) 1 / 2$ and hu that determines the optical bandgap (Eg).

From Table 3, Eg was found to be in the range of 5.33-5.48 eV for oxygen/argon nanocrystalline $\mathrm{ZrO}_{2}$ films.

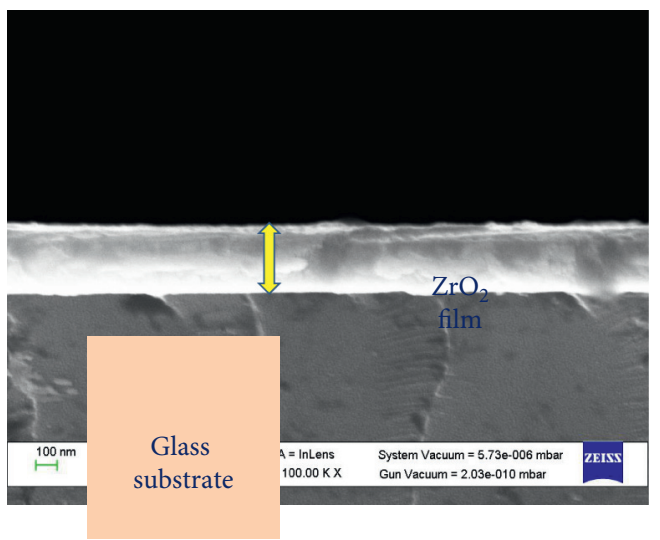

Figure 7: X-section SEM picture of $\mathrm{ZrO}_{2}$ sample.

Results found that when oxygen force increases, oxygen concentration also increases that helps in increasing the bandgap for prepared films regardless in the usage of active gas [37]. The XRD pattern too explains this phenomenon of increasing bandgap. The grain size decreases with increased oxygen/argon gas ratio, as shown in Table 2, and calculated bandgap values also indicate the same [34].

Width of the sample was measured using a scanning electron microscopy (SEM). Figure 7 shows X-section picture of the $\mathrm{ZrO}_{2}$ surface. A surface profilometer was used to measure the width of the prepared sample. Also, transmission data were calculated for the same using the equation as follows [37]:

$$
d=\frac{M \lambda_{1} \lambda_{2}}{2\left[n\left(\lambda_{1}\right)\left(\lambda_{2}-n\left(\lambda_{2}\right) \lambda_{1}\right)\right]} .
$$

\section{Conclusions}

Nanocrystalline $\mathrm{ZrO}_{2}$ thin film coating was deposited under varying oxygen/argon gas ratios in the range of (0.25-1.0) on glass substrate by the sputtering technique. The orientation of the crystalline structure was found at $(-111)$ direction for the gas ratio at 0.25 , which was similar to the bulk $\mathrm{ZrO}_{2}$, but as the oxygen/argon gas ratio increases from $0.5-1.0$, the film crystallinity was reduced, and the orientation shifts from $(-111)$ to (111) plane. However, the target property, that is, aquaphobicity, decreases as the gas ratio increases. In addition, there was a slight increase in transparency and bandgap towards increasing gas ratio on the cost of reduced aquaphobicity. Hence, the gas ratio at 0.25 was chosen as an optimum parameter, and the maximum contact angle was 
found to be $107.45^{\circ}$ at this ratio ensuring that the deposited thin film was aquaphobic. In addition, a higher deposition rate $(9.05 \mathrm{~nm} / \mathrm{min})$, bigger grain size $(77.01 \mathrm{~nm})$, better transparency $(\sim 90 \%)$, and refractive index (2.15) were found as deposited at 0.25 oxygen/argon gas ratio. Thus, a 0.25 gas ratio was chosen as the most favorable gas ratio in establishing aquaphobic coating for outdoor insulators to mitigate the contamination problem.

\section{Data Availability}

The data used to support the findings of this study are included in the article. Should further data or information be required, these are available from the corresponding author upon request.

\section{Conflicts of Interest}

The authors declare that they have no conflicts of interest.

\section{References}

[1] IEEE Working Group, IEEE Trans. Power Appl. Syst. 91, pp. 1948-11954, 1972.

[2] P. J. Lambeth, "Effect of pollution on high-voltage outdoor insulators," Proceedings of the Institution of Electrical Engineers, vol. 118, no. 9R, pp. 1107-1130, 1971.

[3] R. S. Gorur, E. Cherney, C. de Tourreil et al., "Protective coatings for improving contamination performance of outdoor high voltage ceramic insulators," IEEE Transactions on Power Delivery, vol. 10, no. 2, pp. 924-933, 1995.

[4] M. A. R. M. Fernando and S. M. Gubanski, "Leakage currents on non-ceramic insulators and materials," IEEE Transactions on Dielectrics and Electrical Insulation, vol. 6, no. 5, pp. 660-667, 1999.

[5] N. Yoshimura, S. Kumagai, and S. Nishimura, "Electrical and environmental aging of silicone rubber used in outdoor insulation," IEEE Transactions on Dielectrics and Electrical Insulation, vol. 6, no. 5, pp. 632-650, 1999.

[6] R. S. Gorur, "Failure modes of porcelain and toughened glass suspension insulators," IEEE electrical insulation conference, pp. 221-225, 2011.

[7] K. J. Hubbard, D. G. Schlom, and J. Mater, "Thermodynamic stability of binary oxides in contact with silicon," Journal of Materials Research, vol. 11, no. 11, pp. 2757-2776, 1996.

[8] G. D. Wilk, R. M. Wallace, J. M. Anthony, and J. Appl, "High$\kappa$ gate dielectrics: current status and materials properties considerations," Journal of Applied Physics, vol. 89, no. 10, pp. 5243-5275, 2001.

[9] J. Robertson and J. Vac, "Band offsets of wide-band-gap oxides and implications for future electronic devices," Journal of Vacuum Science \& Technology B: Microelectronics and Nanometer Structures, vol. 18, no. 3, 2000.

[10] M. Houssa, High-K Gate Dielectrics, Institute of Physics Publishing, Bristol, England, 2004.

[11] M. L. Green, E. P. Gusev, R. Degraeve, and E. L. Garfunkel, "Ultrathin," Journal of Applied Physics, vol. 90, no. 5, pp. 2057-2121, 2001.

[12] D. Chi and P. C. McIntyre, "Thermal stability and energyband alignment of nitrogen-incorporated $\mathrm{ZrO} 2$ films on Si(100)," Appl. Phys. Lett.vol. 88, Article ID 232901, 2006.

[13] C. M. Wang, S. Azad, S. Thevuthasan, V. Shutthanandan, D. E. McCready, and C. H. F. Peden, "Distortion of the oxygen sublattice in pure cubic- $\mathrm{ZrO}_{2}$," Journal of Materials Research, vol. 19, no. 5, pp. 1315-1319, 2004.

[14] J. Robertson, "Interfaces and defects of high-K oxides on silicon," Solid-State Electronics, vol. 49, no. 3, pp. 283-293, 2005.

[15] M. Copel, M. Gribelyuk, and E. Gusev, "Structure and stability of ultrathin zirconium oxide layers on $\mathrm{Si}(001)$," Applied Physics Letters, vol. 76, no. 4, pp. 436-438, 2000.

[16] C. M. Lopez, N. A. Suvorova, E. A. Irene, A. A. Suvorova, and M. Saunders, " $\mathrm{ZrO}_{2}$ film interfaces with $\mathrm{Si}$ and $\mathrm{SiO}_{2}$," Journal of Applied Physics, vol. 98, no. 3, Article ID 033506, 2005.

[17] L.-M. Chen, Y.-S. Lai, and J. S. Chen, "Influence of pre-deposition treatments on the interfacial and electrical characteristics of $\mathrm{ZrO}_{2}$ gate dielectrics," Thin Solid Films, vol. 515, no. 7-8, pp. 3724-3729, 2007.

[18] J. Okabayashi, S. Toyoda, H. Kumigashira et al., "Chemical reaction and metallic cluster formation by annealing-temperature control in $\mathrm{ZrO}_{2}$ gate dielectrics on Si," Applied Physics Letters, vol. 85, no. 24, pp. 5959-5961, 2004.

[19] T. Yamaguchi, H. Satake, N. Fukushima, and A. Toriumi, "Study on $\mathrm{Zr}$-silicate interfacial layer of $\mathrm{ZrO}_{2}$ metal-insulatorsemiconductor structure," Applied Physics Letters, vol. 80, no. 11, pp. 1987-1989, 2002.

[20] U. S. Patel, K. H. Patel, K. V. Chauhan, A. K. Chawla, and S. K. Rawal, "Investigation of various properties for zirconium oxide films synthesized by sputtering," Procedia Technology, Elsevier, vol. 23, , pp. 336-343, 2016.

[21] R. Mahapatra, J.-H. Lee, S. Maikap et al., "Electrical and interfacial characteristics of ultrathin $\mathrm{ZrO}_{2}$ gate dielectrics on strain compensated $\mathrm{SiGeC} / \mathrm{Si}$ heterostructure," Applied Physics Letters, vol. 82, no. 14, pp. 2320-2322, 2003.

[22] S. Harasek, A. Lugstein, H. D. Wanzenboeck, and E. Bertagnolli, "Slow trap response of zirconium dioxide thin films on silicon," Applied Physics Letters, vol. 83, no. 7, pp. 1400-1402, 2003.

[23] R. Puthenkovilakam and J. P. Chang, "Valence band structure and band alignment at the $\mathrm{ZrO}_{2} / \mathrm{Si}$ interface," Applied Physics Letters, vol. 84, no. 8, pp. 1353-1355, 2004.

[24] A. Stesmans and V. V. Afanas'ev, "Si dangling-bond-type defects at the interface of (100)Si with ultrathin layers of $\mathrm{SiOx}$, $\mathrm{Al}_{2} \mathrm{O}_{3}$, and $\mathrm{ZrO}_{2}$," Applied Physics Letters, vol. 80, no. 11, pp. 1957-1959, 2002.

[25] J. M. Howard, V. Craciun, C. Essary, and R. K. Singh, "Interfacial layer formation during high-temperature annealing of $\mathrm{ZrO}_{2}$ thin films on Si," Applied Physics Letters, vol. 81, no. 18 , pp. 3431-3433, 2002.

[26] M. Ohring, The Materials Science of Thin Films, Academic Press, San Diego, CA, USA, 1992.

[27] S. Rahmane, M. Djouadi, S. Abdou, M. Aida, and N. Barreau, "International conference on plasma surface engineering," in Proceedings of the 13th International Conference on Plasma Surface Engineering, pp. 311-316, Garmisch-Partenkirchen, Germany, September 2012.

[28] B. D. Cullity, Elements of X ray Diffraction, Addison-Wesley, Massachusetts, MA, USA, 2nd edn edition, 1978.

[29] C. V. Ramana, M. Vargas, G. A. Lopez, M. Noor-A-Alam, M. J. Hernandez, and E. J. Rubio, "Effect of oxygen/argon gas ratio on the structure and optical properties of sputter-deposited nanocrystalline $\mathrm{HfO}_{2}$ thin films," Ceramics International, vol. 41, no. 5, pp. 6187-6193, 2015.

[30] J. C. Palacios, G. J. Cruz, M. G. Olayo, and J. A. ChávezCarvayar, "Characterization of hydrophobic and hydrophilic polythiophene-silver-copper thin film composites synthesized 
by DC glow discharges," Surface and Coatings Technology, vol. 203, no. 20-21, pp. 3032-3036, 2009.

[31] R. N. Wenzel and J. Phys, "Surface roughness and contact angle," The Journal of Physical and Colloid Chemistry, vol. 53, no. 9, pp. 1466-1467, 1949.

[32] J. C. Manifacier, J. Gasiot, and J. P. Fillard, "A simple method for the determination of the optical constants $n, k$ and the thickness of a weakly absorbing thin film," Journal of Physics E: Scientific Instruments, vol. 9, no. 11, pp. 1002-1004, 1976.

[33] D. Devendranath, Channakeshava, and A. D. Rajkumar, "Leakage current and charge in RTV coated insulators under pollution conditions," IEEE Transactions on Dielectrics and Electrical Insulation, vol. 9, no. 2, pp. 294-299, 2002.

[34] C. V. Ramana, R. S. Vemuri, I. Fernandez, and A. L. Campbell, "Size-effects on the optical properties of zirconium oxide thin films," Applied Physics Letters, vol. 95, no. 23, Article ID 231905, 2009.

[35] R. Asal and H. N. Rutt, "Optical properties of laser ablated gallium lanthanum sulphide chalcogenide glass thin films prepared at different deposition laser energy densities," $O p$ tical Materials, vol. 8, no. 4, pp. 259-268, 1997.

[36] J. Tauc and J. Tauc, Eds., Amorphous and Liquid SemiconductorPlenium Press, New York, NY, USA, 1974.

[37] V. Dave, P. Dubey, H. O. Gupta, and R. Chandra, "Effect of sputtering gas on structural, optical and hydrophobic properties of DC-sputtered hafnium oxide thin films," Surface and Coatings Technology, vol. 232, pp. 425-431, 2013. 